\title{
The use of satellite technology for digital citizenship: experimental tests and investigation methods
}

\author{
Paola D'Antonio ${ }^{1, *}$, Vincenzo Nunzio Scalcione ${ }^{2}$, Francesca Romano ${ }^{3}$ \\ ${ }^{1}$ School of Agricultural, Forestry, Food and Environmental Sciences (SAFE) University of Basilicata. Potenza, Italy \\ ${ }^{2}$ University of Basilicata. Potenza, Italy \\ ${ }^{3}$ University of Rome La Sapienza, Rome, Italy
}

How to cite this paper: D'Antonio, P., Scalcione, V. N., Romano, F. (2020) The use of satellite technology for digital citizenship: experimental tests and investigation methods. International Journal of Food Science and Agriculture, 4(1), 90-96.

DOI: $10.26855 /$ ijfsa.2020.03.013

Received: December 9, 2019

Accepted: January 2, 2020

Published: March 17, 2020

*Corresponding author: Paola D'Antonio, School of Agricultural, Forestry, Food and Environmental Sciences (SAFE) University of Basilicata. Potenza, Italy.

Email: vincenzoscalcione@gmail.com

\begin{abstract}
This research is the result of an experiment that has placed the use of technologies and the use of satellite guidance instruments at the center of its interests to support human capabilities. This is an experiment that has considered the texture of the soil as the main parameters, according to their equivalent diameter. The use of agricultural machines had the purpose of creating, in the scenario of experimental tests, the conditions that would allow to provide the data on which to establish, among the pairs of systems used, the one capable of guaranteeing the best quality of work. The main parameters considered during the analysis of the samples are those concerning the texture of the soils, that is, the constitution of the soils expressed as the ratio between the particles of different sizes that make them up, according to their equivalent diameter. In fact, in line with what is asserted by many cognitive psychologists, the present research wanted not only to observe and measure the impact that IT tools have had in everyone's daily life, but also to allow us to hypothesize design lines that converge and give shape to a new digital citizenship, through the promotion of digital skills.
\end{abstract}

\section{Keywords}

satellite technology, digital citizenship, teaching, skills, technology education

\section{Introduction}

This research is the result of an activity carried out on agricultural land, with a total area of 53 hectares. This experiment has put the use of technology at the center of its interests, which must be used to support human capabilities. In fact, according to what has been said by many cognitive psychologists, today it is actually necessary to support the development of cognitive technologies, focused on the development of human skills and not only those of the machine [1]. They must therefore be carefully designed, taking into account the users' capabilities. The question is of great importance, and it is sufficient, to understand its importance, to think of the changes that technological development has brought about in the field of knowledge. Indeed, following the use of new technologies and mobile devices, the changes have become increasingly evident. However, in some cases, the design models adopted have placed technology and not man at the center. In this way, the artifacts are not aimed at improving human cognitive skills." It must be considered that external representations help man's cognitive abilities (for example, help him memorize data or perform calculations) and determine the degree of ease with which the various problems will result. Therefore, cognitive artifacts modify the tasks we have to carry out" [2].

\section{Material and methods}

Compared to the experimentation carried out, in allocative terms, the agricultural land is located in Marina di Ginosa 
(TA) at C.da Pantano, Montedoro (Latitude $40^{\circ} 27.23625$ North, Longitude: $16^{\circ} 48.70149$ East), about $3 \mathrm{~km}$ from a crossroads on State Road 106 Jonica; mainly cereals (corn, wheat, etc.) and vegetables (fennel, pea, tomato, green beans, watermelon, etc.) are grown.

On the days when the surveys were conducted, the temperatures were around $22-25^{\circ} \mathrm{C}$, in the hottest hours of the day, with a relative humidity $(\mathrm{RH})$ between $60 \%$ and $65 \%$, always during the hottest hours of the day.

This research focuses on the technical-economic analysis of the use of satellite guidance tools. The experiments, carried out in different periods, were carried out on eight different plots of land (A1, A2, A3, A4, A5, A6, A7, A8), for a total area of 8.35 hectares.

LANDSAT representation of the area subject to the experimental tests [3]

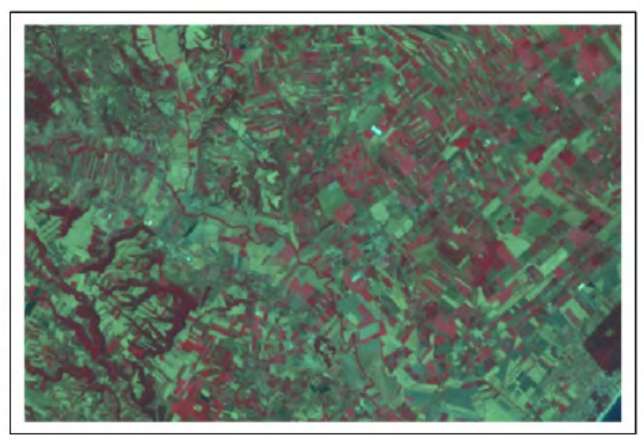

The agricultural land, completely flat and positioned at 30 meters above sea level, has a rectangular shape, with a side greater than $120 \mathrm{~m}$, on average, and a smaller side of $80 \mathrm{~m}$ (all contiguous with a total area of $8,35 \mathrm{ha}$ ). Since these are contiguous agricultural land and land of the same origin, as well as of the same processing and with the same crops, the chemical-physical analyzes have led to similar results.

The main parameters considered, during the analysis of the samples, were those of the plot of the soils, that is, the relationship between the particles of different sizes that make them up, in relation to their equivalent diameter. Lands are divided into three classes:

Scheme differentiation of agricultural land

\begin{tabular}{|c|l|}
\hline Sand & particles with a diameter between 0.02 and $2.0 \mathrm{~mm}$ \\
\hline silt & particles with a diameter between 0.002 and $0.02 \mathrm{~mm}$ \\
\hline clay & particles with a diameter between 0.002 and $0.02 \mathrm{~mm}$ \\
\hline
\end{tabular}

The knowledge and study of weaving is very important, because it serves to improve the understanding of the analytical data collected, in relation to fertilization. In fact, for example, the high sand content favors nitrogen losses; all this due to the greater erosion of the nutrients. A higher quantity of fertilizer is therefore necessary, while high clay contents create difficulties for the movement of the nutrients, but at the same time they reduce losses and create stagnation phenomena. In loamy soils, the poor mobility of nutrients is even greater. It must be considered that the nutritional elements are mobile elements and the composition of the lotus varies every year, depending on: cultivation in progress; erosion level; increase in cultivation operations. The plot of a land, on the other hand, hardly changes anything, unless one intervenes with deep and repeated working of the same land. There are mainly two sampling methods:

- Systematic sampling: it consists in dividing the field into many equal areas, forming a grid, in which the samples will be collected. A value is then assigned to each individual area, relative to the result of the analysis. All this is done by using a satellite receiver to identify the point examined.

- Selective sampling: it involves the identification of areas of the ground with the same pedological or productive characteristics, through the study of the production maps and the samplings of previous years. 


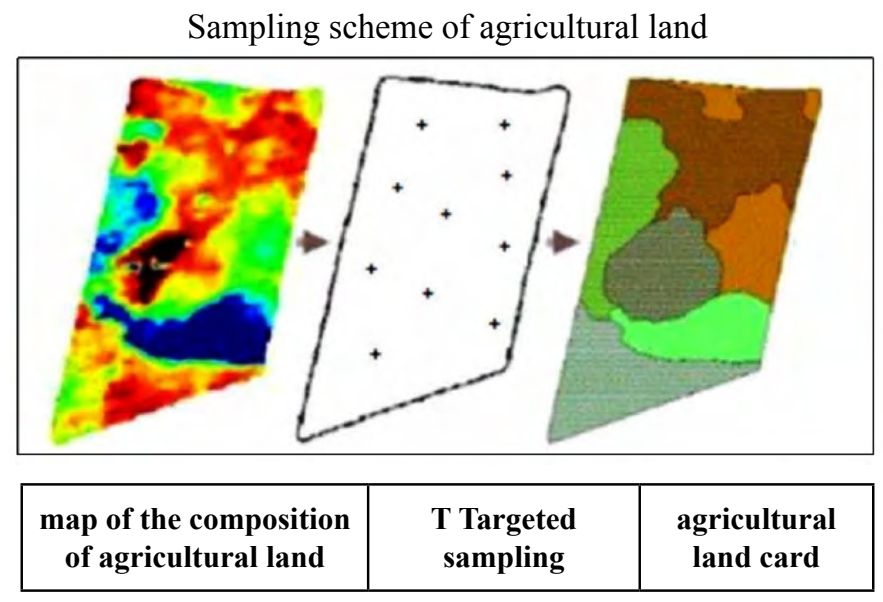

In precision farming, sampling represents a fundamental step for the knowledge and the management of the variability of a plot of land, especially if it is combined with the mapping of yields to maximize the effectiveness of execution.

Sampling represents the first step of a chemical analysis. It consists of taking a sample and taking it to the laboratory; in this regard, it is essential to identify the number of samples to be taken and the sites from which to take the samples, inside the plot of land [4].

Preliminary to any sampling are the climatic conditions and the color of the soil, that is to say: the area in question must be subject to the same climatic regime, a situation verified in this survey; as regards the color, in the thematic area of the investigation it is possible to trace the different colors, which correspond to the different chemical-physical characteristics of the agricultural land.

In our case, the rectangular conformation of the graphs suggested the need to collect 10 specimens. The execution of the 10 specimens was carried out along the diagonals that pass through the vertices of the plot of land, identifying the first sampling site at the intersection of the two diagonals. The other sampling sites were located on each of the halfangles, far from the perimeter of the ground; trespassing has been avoided in the perimeter areas of the plot, between a land and that of the adjacent area (it is easy for it to have different characteristics). Contaminations were avoided, which would have distorted the samples and therefore the results. In consideration of this, the sampling along the diagonals were carried out at the intersection points between the diagonal and the segment, having a length equal to $10 \%$ of the diagonal, and located orthogonally, with respect to the longer side of the edge of the plot of land [5].

The sampling thickness was $20 \mathrm{~cm}$, for each of the ten basic samples. The ten samples were collected between 15:30 and 16:30 on September 15, 2011. After collection, they were placed in a single bag, mixed and delivered to the Laboratory of the Chemistry Department of the University of Basilicata, for the related analysis.

\section{Result}

The investigations conducted on this sample indicated an average particle size composition, consisting of $23.8 \%$ of sand, $43.8 \%$ of silt and $32.4 \%$ of clay; this means that the soil can be classified according to the modified American Ground Survey method as clay.

The details of the analyzes conducted can be found in the following report:

Ground analysis performed bythe Laboratory of the Department of Chemistry of the University of Basilicata

\begin{tabular}{|l|c|l|l|l|}
\hline Sample & & & & \\
\hline Sand \% & 23,8 & & & \\
\hline Clay \% & 76,2 & & & \\
\hline permanent withering point & 0,43 & $\begin{array}{c}\mathrm{cm}^{3} \text { water } / \mathrm{cm}^{3} \\
\text { ground }\end{array}$ & 17,5 & $\mathrm{gr} / \mathrm{gr}$ \\
\hline
\end{tabular}




\begin{tabular}{|c|c|c|c|c|}
\hline humidity equivalent & & & 41,30 & $\mathrm{gr} / \mathrm{gr}$ \\
\hline field capacity & 0,54 & $\begin{array}{c}\mathrm{cm}^{3} \text { water } / \mathrm{cm}^{3} \\
\text { ground }\end{array}$ & 35,86 & $\mathrm{gr} / \mathrm{gr}$ \\
\hline Apparent density & 1,18 & grams $/ \mathrm{cm}^{3}$ & 1,19 & $\mathrm{gr} / \mathrm{gr}$ \\
\hline Saturation & 0,55448 & $\begin{array}{c}\mathrm{cm}^{3} \text { water } / \mathrm{cm}^{3} \\
\text { ground }\end{array}$ & 0 & $\mathrm{gr} / \mathrm{gr}$ \\
\hline $\begin{array}{l}\text { saturation hydraulic } \\
\text { conductivity }\end{array}$ & 0,296431 & $\mathrm{~cm} /$ hour & 0,30 & $\mathrm{gr} / \mathrm{gr}$ \\
\hline water available & 219,44 & millimeters/ meter & 10,50 & $\mathrm{gr} / \mathrm{gr}$ \\
\hline $\mathrm{ph}$ & 8,02 & & & \\
\hline C.E. & 7,35 & $\mu \mathrm{S}$ & & \\
\hline \multicolumn{5}{|l|}{ Granulometry } \\
\hline big sand & 4,2 & $\%$ & & \\
\hline thin sand & 19,6 & $\%$ & & \\
\hline big silt & 10,8 & $\%$ & & \\
\hline thin silt & 33,0 & $\%$ & & \\
\hline clay & 32,4 & $\%$ & & \\
\hline $\begin{array}{l}\text { characteristics of } \\
\text { agricultural land }\end{array}$ & clay ground & & & \\
\hline
\end{tabular}

Map and histogram refer to the presence of silt in the soil: the area south of the blue texture of the earth indicates a lower composition of silt (between 5.48-8.17\%), while the red-black part represents the area with the highest silt content (about 27.1\%).

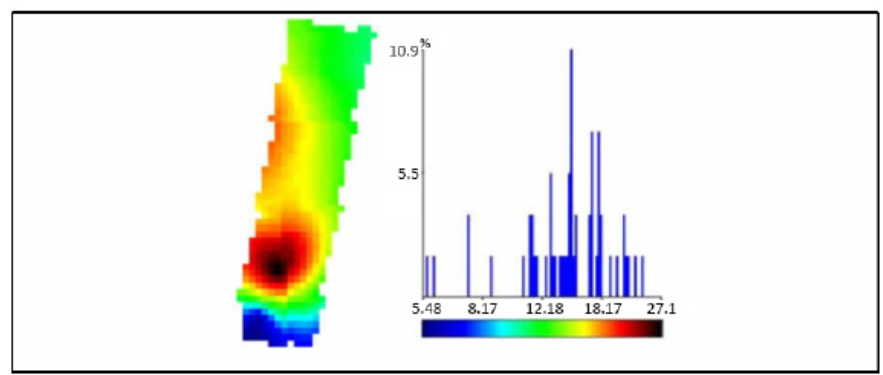

Map and histogram refer to the presence of clay in agricultural land: the southern area, blue in color, indicates a smaller clay composition (between 8.74-11.69\%), while the northern area, red- black, it is characterized by a greater quantity of clay (between 20.88-27.92\%).

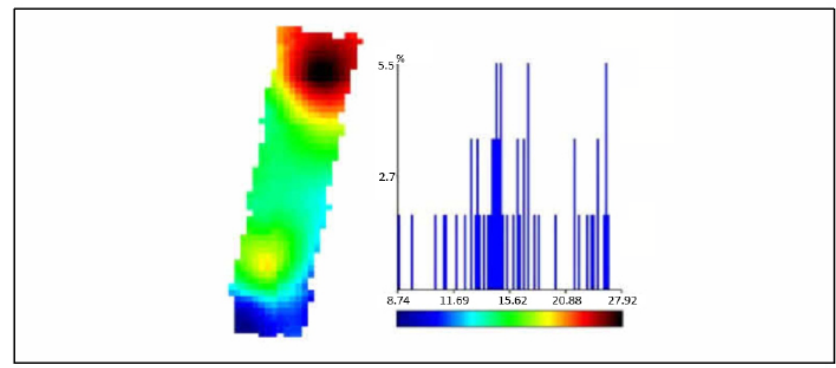


Map and histogram refer to the presence of sand in the ground: the area south of the plot of land, red in color, indicates a greater composition of sand between $35.80-42.30 \%$, while the two parts are colored blue, which represents two areas with the lowest composition, between $13.35-20.2 \%$. Most of the soil has a composition of about $23.7 \%$ of sand, indicated by the green color.

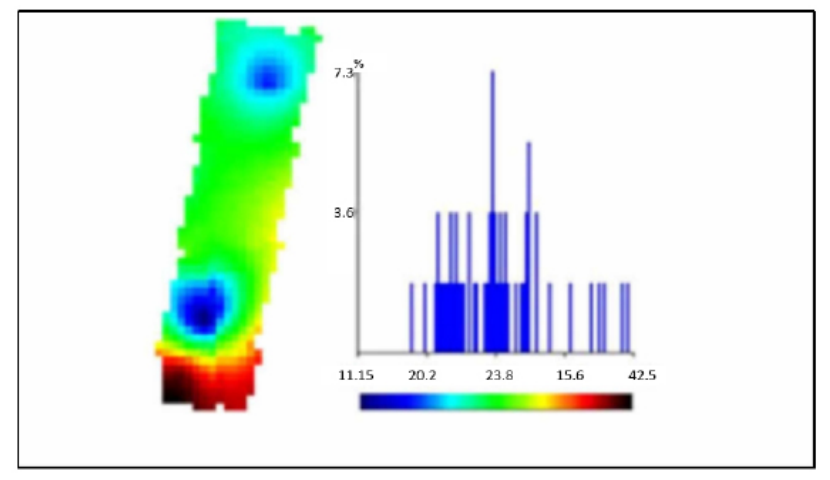

\section{Discussion}

Field investigations were conducted on two different satellite guidance devices, and with two different GPS signal correction systems:

- the EZ - Steer, with RTK precision.

- Integrated Autopilot, with EGNOS precision.

EZ - Steer has an assisted driving system; the management of the direction of the tractor takes place, in fact, by means of an action, on a steering wheel, of a motorized roller; the latter is, in turn, controlled by the control unit, housed in the tractor cabin. This system does not exceed an aggression of over 90 points (on a scale ranging from 50 to 150). This is due to a motor reaction to the course correction pulses, issued by the control unit, not instantaneous; another reason lies in the slight slipping of the roller on the steering wheel. In fact, on this EZ-Steer system it has been possible to observe that it is in an excessive correction, also taking advantage of the RTK precision and setting an aggressiveness of over 90 points. The course corrections, provided by the T2 control unit, are so sudden that they cannot be managed millimetrically by the roller positioned on the steering wheel. Therefore, the tractor cannot perfectly follow the direction assigned via GPS, but rather accentuates the sinusoidal frequency inside it [6].

This problem, as it was also possible to verify, is less felt on the paved road; when the tractor no longer rests on a yielding or disconnected shelf, the EZ-Steer is subject to fewer corrections, in the unit of time; therefore it is possible to bring aggression even beyond 90 points. It is clear that this is an operational circumstance that generally does not occur with a tractor, which is instead designed to work on dirt roads, on difficult surfaces [7].

The autopilot, on the other hand, has an integrated system, in the sense that the driving control is no longer carried out on the steering wheel, but takes place directly with the hydrostatic system of the tractor, through a hydraulic management control unit installed on the engine compartment level.

This control unit, in turn, communicates with the T3 control unit, housed in the control cabin. The T3 control unit communicates not only with the GPS antenna, but also with proximal sensors to the wheels; these sensors indicate, to the control unit T3, how much the feed axis deviates from the orthogonal of the tractor. Precisely because the Autopilot system acts on the hydraulic circuit, unlike the EZ-Steer, it allows you to work with aggression up to 135 points, before going over-corrected. This means that the Autopilot has a remarkable capacity to maintain the correct trajectory, even on very uneven terrain [8].

With regard to the accuracy of the GPS signal, we recall instead that: with the EGNOS correction of the error it is possible to obtain a positioning accuracy of $20 \mathrm{~cm}$, and a repeatability of plowing, year after year, of $90 \mathrm{~cm}$ (and a free service ); the RTK, instead, consists of a high precision technology, which translates into an accuracy between $2.5 \mathrm{~cm}$ consecutive plowing and $2.5 \mathrm{~cm}$ repeatability year after year.

In performing the tests, the tractor used was the New Holland T7060, while, as operating machines, the following were used: rotary harrow, Alpego DG-400; stoneburiers, Forigo DG-45; the PAntera 420 mechanical hoe; the silver 66/15 
scrambling plow.

These operating machines were used to recreate, in the experimental test scenario, the conditions that would allow the supply of data on which to establish, between the two pairs of systems, the one capable of guaranteeing the best quality of work, in addition to knowledge and dynamics integration of experiences, information, values, specific skills; this experimentation is mainly linked to organizational procedures and processes, strategies, practices [9].

\section{Conclusion}

Looking at new communication technologies as pedagogical-didactic technologies tout court means not taking into due consideration the centrality of educational intentionality. It is therefore a question of starting a reflection that highlights how technology has the purpose of completing human capacities, helping us in those activities that are less congenial to us. The goal of many cognitivist psychologists today is, in fact, to support the development of cognitive technologies centered on man, not on the machine [10].

They must therefore be carefully designed, keeping in mind the users' abilities. To this end, the identification of the characteristics of teaching methods, which have used the latest interactive technologies, could be relevant. It is therefore also necessary to understand which epistemological paradigms to inspire in the execution of these activities; analyze the difficulties and critical issues encountered in carrying out these activities; underline the value assigned to interdisciplinarity and the space for collaborative learning. In particular, the maintenance and usability of technological resources are the main factors that should influence the project objectives. It is also important to remember how information and communication technologies have enormous potential to support autonomous learning, collaborative knowledge building and skill development. It is a question of referring to the new pedagogical reflection on new technologies and teaching experiences, in the context of action research projects [11].

It is therefore a question of contributing to the elaboration of a mentality that does not isolate itself in individualism, in the segmentation and fragmentation of everything. Instead, it would serve to build synergies of action, in the "hologram" vision of all the different aspects that are integrated in strategies, interventions, effective and efficient skills, for the development of individuals. In the didactic field, it has been understood that the characteristics of pedagogy by objectives (i.e. the homogenizing effect) distort the procedures to improve the teaching practice, because not everything is observable in terms of behavior. The information paradigm would like to bring everyone, despite the different conditions, to common standards of education. It is the pedagogy of the curriculum, in which the transmission-acquisition of knowledge is central, becoming a didactic object. It is knowledge, considered by objectivists as a historical, universal, objective truth, mirrored by a rational, impartial and objective mind. This vision, which presupposes the existence of an objective external reality, flows, as we have said, into teaching understood as the transfer of knowledge [12].

It is not a question, therefore, of observing and measuring only the impact that computer tools have had in everyone's daily life, but of hypothesizing project lines that flow together and give shape to a "collective system of sensitivity, intelligence and coordination that will constitute, in the near future, the infrastructure of a civilization on a world scale" [13]. In this sense, the use of satellite technology becomes a tool for the promotion of a new citizenship, based on the possession of digital skills, capable of promoting participation in the knowledge society. In this perspective, the use and verification of the tools becomes the way through which to develop a new teaching of technologies, based on experience, and on the use of the same, in the large laboratory of the real world.

\section{References}

[1] Fierli, M. (2003) Tecnologie per l'Educazione. Laterza,Roma-Bari.

[2] Zhang, J., Norman, D. (1994) Representations in distributed cognitive tasks. Cognitive Science, 18: 87-122.

[3] Ministry of the Environment and Protection of the Territory and the Sea National Geoportal (2020) http://www.pcn. minambiente.it/mattm/en/the-national-geoportal/

[4] Pierce, F. J., Nowak, P. (1999) Aspects of precision agriculture, Advances in Agronomy, 67: 1-85.

[5] Bongiovanni, R., Loweenberg-De Boer. J. (2004) Precision Agricolture and Sustainability, Precision Agricolture, 5: 359-387.

[6] Perez-Ruiz, M., Carballido, J., Aguera, J., Gil, J.A. (2011) Assessing GNSS correction signals for assisted guidance systems in Agricultural vehicles. Precision Agriculture, 12(5): 639-652. 
[7] Robert, P.C., Rust, R.H., Larson, W.E. (1993) Proceedings of soil specific crop management: a workshop on research and development issues, University of Minnesota, Madison USA..

[8] Anthony, R.N. (1965) Planning and control systems: a framework for analysis. Harvard University Press, Cambridge.

[9] Davemport, T., Prusak, L. (2000) Il sapere del lavoro. Come le aziende possono generare, codificare e trasferire conoscenza. Etas, Milan.

[10] Faiella, F. (2010) Apprendimento, tecnologia e scuola nella società della conoscenza. TD Tecnologie Didattiche, 50: 25-29.

[11] Sartori, A., Basso, L., Bertocco, M. (2005) Agricoltura di precisione. Concetti teorici e applicazioni pratiche. Edizioni L'Informatore Agrario, Verona.

[12] Varisco, B.M. (1998) Nuove tecnologie per l'apprendimento. Garamond, Roma.

[13] Maragliano, R. (1998) Lo spazio multimediale è un modello di filosofia, Telema, 4: 48. 